\title{
Enkele motiewe vir 'n eietydse verstaan van die belydenisskrifte
}

\section{J H Koekemoer \\ Dekaan: Fakulteit Teologie (Afd A) \\ Universiteit van Pretoria}

\begin{abstract}
Reasons for a comtemporary re-interpretation of creeds

The present century has seen an increasing opposition to creeds and doctrinal statements of faith. The question for the church and theology is how to read the creeds in such a way that it will not deprive us from our own responsibility to Scripture. In order to do just that a reinterpretation of the creeds is necessary. In this reinterpretation there should be a recognition of historical and cultural relativity. We do not experience our world in the same way as premodern people did. Any attempt to leave ecclesiastical doctrines in an unchangeable form would result in the increasing loss of the meanings of those doctrines.
\end{abstract}

\section{INLEIDING}

Die vraag na die betekenis van die belydenisskrifte vir die huidige tyd bring tegelyk die vraag na 'n eietydse verstaan van die geskrifte na vore. Gesien in die lig van die histories gesitueerdheid van die belydenisskrifte moet ook duidelikheid verkry word oor motiewe vir 'n eietydse verstaan van die belydenisskrifte. In die verband blyk die volgende opmerking van Jüngel (1995:82) van betekenis te wees: 'In Swabia people say of something that took place long ago that it is so long ago since it happened that it can hardly be true any more. So Christ died for our sins so long ago that it can hardly be true any more'. Wanneer hierdie stelling op die onderwerp van hierdie artikel toegepas word, beteken dit dat die huidige kerklike belydenisskrifte so lank gelede verwoord is dat iemand kan redeneer dat dit nouliks in die huidige konteks meer betekenisvol kan wees.

In die aangehaalde artikel van Jüngel (1995:82) word daar verder geredeneer dat dit juis die taak van die dogmatiek is, nieteenstaande die opmerking van die mense in Swabië, om nie alleen die dood van Jesus nie maar ook die lewe van Jesus van betekenis te maak vir die huidige geslag. Dit gaan in dogmatiese besinning oor die moontlikheid van 'n kontemporêre geloof in Jesus Christus. 
Wanneer dít gesê is, is dit duidelik dat die Christendom wat met tekste uit die verlede werk waarin die waarheid oor God onder woorde gebring is, met ' $n$ hermeneutiese probleem te kampe het. Hierdie probleem manifesteer daarin dat 'n gesaghebbende tekstradisie geïnterpreteer moet word binne 'n omgewing waarop dit nie direk betrekking het nie (Omen 1975:1). Wanneer verder in gedagte gehou word dat die huidige geslag ' $n$ bepaalde negatiewe houding teenoor leerstellige uitsprake openbaar (Crawford 1976:18-25), word die saak van hoe en of sulke uitsprake vir 'n kontemporêre geloof tog wel van betekenis is, van wesenlike belang. Daar moet in gedagte gehou word dat die wekroep van baie wat die gedagterigting steun dat konfessies verouderd is, teruggaan na die gedagte van Sola Scriptura.

No document drawn up by man is to be put in place of that which is the supreme rule of faith and practice. Throughout the century many writers and preachers pleaded for the liberty of every man to search the scripture for himself, the right of private judgment, and the proper use of consience in matters of faith. They contended against the Church's practice of imposing articles of faith upon its members which were not expressed in the words of scripture, and in charging men with heresy who refused to subscribe to her formulas.

(Crawford 1976:13, 14)

Aan die ander kant is daar ook steeds diegene wat pleit vir die behoud van belydenisuitsprake en ernstig worstel met die vraag na die betekenisgewing van sulke uitsprake binne nuwe kontekste. Op voetspoor van onder andere Martin Luther word daar nie gepleit vir 'n dogmalose Christendom nie. Daar word daarop gewys dat vir Luther die leer van die kerk, veral in die eerste vier eeue, as gesaghebbend beskou is. Hierdie sogenaamde doctrina Christiana, het Luther ge-oordeel, is gesaghebbend tot die mate waarin dit daarin slaag om die lewende krag van die evangelie te bewaar (Omen 1975: 2).

Om uit te maak wat die lewende krag van die evangelie binne die leeruitsprake is, sal die moontlikheid al dan nie van die onderskeiding tussen verpakking en essensie in ag geneem moet word. Derhalwe behoort die konteks waarbinne die uitsprake gestalte gekry het, ernstig geneem te word. Om enigsins hierby uit te kom sal in gedagte gehou moet word dat geloofsbelydenisse, belydenisskrifte en dogmas ' $n$ verskeidenheid rolle in die geskiedenis van die Christendom vervul en steeds vervul. 
Although often becoming defensive or polemical instruments, intended to exposure and expulsion of persons whose views conflicted with an assumed 'orthodoxy', they have functioned also as positive expressions of belief through which a community obtains identity in a particular time and varied circumstances. To have a self-conscions existence, such a community has to have some kind of symbol of their life together. Even secular communities require pledges or statements of commitment. In the case of religious communities these take an increased importance by virtue of their effort to articulate in some way the theological basis of their common life.

(Hinson 1979:5)

In sy bespreking van die belangrike rol van belydenisuitsprake en hulle ontstaansgeskiedenis binne die vroeg-Christelike tradisie wys Hinson (1979:5vv) daarop dat die Christendom by die konfessionele oriëntasie van die Judaisme aangesluit het. 'n Herinterpretasie het plaasgevind deurdat die verbondsverhouding nou in terme van die ontmoeting met God in Jesus van Nasaret gesien is. En alhoewel in die huidige tydsgewrig gesê moet word dat dogmatiese uitsprake teruggryp na sulke ontwikkelinge in die geskiedenis, bly daar tog 'n bepaalde spanning tussen historiese kennis en dogmatiese verantwoordelikheid bestaan.

To know something (an event, a person) historically means to analise its having-being, its previous existence; and its effect. To account for something (an event, a person) dogmatically means to represent its significance now in the horizon of our current awareness of truth.

(Jüngel 1995:83)

Dat hierdie vrae ten opsigte van die kerklike belydenisskrifte op die tafel geplaas word, is binne die huidige tydsgewrig byna vanselfsprekend. Nie alleen geniet die vraag na die betekenis al dan nie van kerklike belydenisskrifte vandag baie aandag nie, maar daar is selfs ' $n$ vraag na die betekenis van die kerklike boodskap waarvan die wortels in die verlede lê. Wethmar (1977:14) tipeer hierdie probleem tereg as 'n soort identiteitskrisis van die Christendom. Hy stel dat vanweë die historisiteit van die menslike bestaan, die wyse waarop 'n mens verstaan, steeds 'n sekere horisontaliteit vertoon. Die implikasie hiervan vir die geskiedenis van die mensheid is dat daardie geskiedenis gekenmerk word deur 'n opeenvolging van kultuurhistoriese tydperke wat elkeen 'n eie konstellasie van verstaansvooronderstellings het. Vir Christene beteken dit dat ook 
hulle geloof in Jesus Christus met verloop van tyd in terme van ander verstaansvooronderstellings uitgespreek moet word as waarin dit deur die eerste Christene gedoen is.

Die vorming van dogmas en belydenisuitsprake was maniere waarop gepoog is om bogenoemde uitdaging die hoof te bied. Hopper (1987:6vv) wys daarop dat hierdie proses die Christelike geloof voor ingewikkelde probleme te staan laat kom het. As voorbeeld verwys hy na die feit dat lede van die vroeë kerk reeds vroeg in die kerk se bestaan genoodsaak was om die verhouding tussen 'God die Vader' en Jesus Christus te verduidelik, veral gesien in die situasie binne die Romeinse ryk waarin hulle hulleself bevind het. Dit was gebruiklik dat van mense verwag. is om die keiser te aanbid. Binne ' $n$ wêreld waar 'n veelheid van gode aanbid is, was so 'n verwagting gewoonlik nie problematies nie. Die Jode het ten opsigte van die reëling 'n uitsonderingsposisie beklee omdat hulle God alleen aanbid het. Die vraag het nou na vore getree: Wat van die Christene?

Ook hulle het geweier om die keiser te aanbid en het aanspraak daarop gemaak dat hulle in die enigste God geglo het. Tog was dit duidelik dat hulle God en Jesus Christus aanbid het. Die vraag was nou: As hulle Jesus aanbid, hoekom nie ook die keiser nie. Die antwoord lyk so vanselfsprekend: Jesus is God. Tog het die vroeë Christene ook besef dat so 'n enkelvoudige oplossing die saak nog meer kompliseer. Hierdie uitspraak bring die mensheid van Jesus immers in gedrang indien dit so enkelvoudig verwoord word. Dit het aanleiding gegee tot die formulering van ' $n$ verskeidenheid antwoorde. Omdat hierdie problematiek die Christendom 'n eksistensiële krisis gedompel het, was dit medeverantwoordelik vir die byeenbring van konsilies om ten opsigte van die sake noodsaaklike leerbeslissings te fel.

Verdere aspekte waarop Hopper wys, is die invloed van politieke strewes en prosesse in die ontstaansgeskiedenis van Christelike dogmas en belydenisuitsprake; terwyl die verandering van die betekenis van bepaalde konsepte ook nie uit die oog verloor behoort te word nie. Hy verwys in hierdie verband onder andere na die rol van Konstantyn by die konsilie van Nicea en die veranderde betekenis wat die begrip 'persoon' deur die loop van die geskiedenis ondergaan het.

Die invloed van sulke faktore in die formulering van dogmas en belydenisuitsprake kan nie ontken word nie. By enige herinterpretasie van die betekenis daarvan vir die huidige tyd sal dit op een of ander wyse ernstig geneem moet word. Die argumente van Hopper (1987:23) oor die noodsaak van die erkenning van die historiese en kulturele relatiwiteit van bogenoemde uitsprake vir die teologie, is in die konteks en die skopus van die artikel van belang.

Die eerste belangrike aspek waarna hy verwys en wat onder andere ook by Otto Weber (1955), Heinrich Ott (1981) en E Jüngel (1995) na vore tree, is dat gewaak moet word teen die gevaar om 'n leerstellige formulering eenvoudig met die waarheid self te identifiseer. 
Omdat teologiese formulerings altyd binne 'n bepaalde taal ontwikkel en gehoor word, is daar bepaalde aannames, oortuigings, vooronderstellings, kulturele waardes en die stand van kennis van mense binne bepaalde tye wat invloede op die formulering van sulke uitsprake uitgeoefen het. Belydenisse sê immers nie net iets oor die een in wie geglo word nie (naamlik God), maar dit sê implisiet ook iets oor hulle wat die belydenis uitspreek.

In sy beredenering van hoe dit die vorming van belydenisuitsprake oor die persoon en werk van Jesus Christus raak, verwys Hopper (1987:14vv) onder andere na die volgende:

The sky hung low in the ancient world. Traffic was heavy on the highway between heaven and earth. Gods and spirits thickly populated the upper air, where they stood in readiness to intervene at any moment in the affairs of mortals. And demonic powers, emerging from the lower world or resident in remote corners of the earth, were a constant manace to human welfare. All nature was alive - alive with supernatural forces.

(Case 1946:1)

Dit het die implikasie gehad dat die verlossingsgebeure binne die konteks verwoord is as ' $n$ stryd tussen God en die duiwel. Bogenoemde het veral in die Verlossingsleer van Gregorius die Grote gestalte gevind (Hopper 1987:16). Binne 'n andersoortige samelewing vind die verlossingsgebeure uitdrukking in die Cur Deus Homo van Anselmus van Canterbury. Die Heidelbergse Kategismus vind dit weer nodig om hierdie struktuur in 'n aangepaste vorm met die oog op die kontemporêre tyd te gebruik.

Bogenoemde voorbeelde gee ' $n$ aanduiding van die historiese en kulturele relatiwiteit wat daar in die verwoording van belydenisuitsprake na vore tree. Dit laat Hopper (1987) konkludeer dat daar 'n negatiewe implikasie hieraan verbonde is, naamlik dat geen leerstellige formulering reglynig met die waarheid geïdentifiseer kan word nie. 'Theological formulations are always developed and heard in particular languages, words and concepts, that they inevitably entail assumptions, convictions, prejudices, cultural values, and state of knowledge of particular peoples in particular times and places' (Hopper 1987:23).

Alhoewel Jüngel (1995:83) dus tereg sê dat 'n spanning tussen dogmatiese verantwoordelikheid en historiese kennis bestaan, beteken dit nie dat historiese kennis onbelangrik is nie. Omdat, volgens Jüngel (1995:83), kennis van God, kennis van die 
openbaring en as sodanig geloofskennis is, beteken dit dat dogmatiese verantwoording ten opsigte van 'n saak nie gegrond kan word in historiese kennis nie: Tog is die veronderstelling hier dat historiese kennis belangrik is, al vorm dit nie die grond van die geloof nie. In sy beredenering van die saak wys Hopper (1987:24) daarop dat 'n studie van die teologie tegelyk na 'n studie van die geskiedenis vra. In die geval van dogmatiese formulerings vra dit nie alleen na 'n studie van die dogmageskiedenis nie, maar ook na geskiedenis in die wyere sin van die woord. Andersins bestaan die wesenlike gevaar van waninterpretasie van die dogmatiese leerstellings. So 'n wye historiese verstaan veroorsaak 'n erkenning van die invloed van leerstellings uit die verlede op die huidige geslag. Tegelyk verskaf dit 'n kritiese perspektief op eie aannames en vooroordele. Selfs die gewone lidmaat van die kerk word deur middel van liedere, preke, gebede, ander literatuur en gebruike immers deur leerstellige uitsprake uit die verlede beïnvloed. Wie onbewus hiervan is, kan maklik die uitsprake met die Skrif identifiseer sonder om te besef dat dit interpretasies binne bepaalde situasies was.

'n Belangrike rede, alhoewel nie die enigste nie, waarom die erkenning van historiese en kulturele relatiwiteit aanvaar moet word, is dat dit die moontlikheid open om te begryp waarom herformulering vir die Christelike teologie so belangrik is. 'To attempt to leave our doctrines in some supposedly unchangeble form would to be to commit ourselves to a gradually increasing loss of the meanings these doctrines had and to require of ourselves an ongoing task of self-deception' (Hopper 1987:24).

Een van die redes vir die pleidooi om herinterpretasie is geleë in die gedagte dat waarheid en dogma nie totaal geïdentifiseer kan word nie. Die saak van historiese en kulturele relatiwiteit bring inderdaad die probleem na vore dat ' $n$ identifikasie maklik tot afgodiese tendense kan lei. Oorvereenvoudiging van die saak is egter net so gevaarlik. Juis omdat ons geen toegang tot die evangelie los van enige menslike formulering het nie, kan waarheid en menslike en historiese formulerings ook nie in waterdigte kompartemente ingedeel word nie. Die gevaar van om die baba met die badwater uit te gooi bly wesenlik (Hopper 1987:25).

Hopper (1987:25) wys in sy verdere beredenering van die saak na die voortgaande debat tussen 'konserwatiewes' en 'liberales'. Hierdie debat word soms met venyn gevoer en ongevraagde etikette word soms aan eerlike teoloë se nekke gehang. 'Konserwatiewes' wil gewoonlik die prestasie van getuies en konsilies uit die verlede wat mede-verantwoordelik was vir die oorlewing van die Christelike geloof en wat in dogmas en leerstellige formulerings na vore tree, bewaar sodat ons ook die evangelie kan hoor. 'Liberales' wys gewoonlik op die noodsaak om die evangelie in die huidige tydsgewrig te hoor. Daarom word baie aandag gegee aan nuwe maniere om die realiteit van God se liefde vry van die formulerings van die verlede, te verwoord. 
'n Bepaalde waarheidselement is in beide die redenasies te vind. Daarom moet gewaak word teen ettiketering en eensydigheid. Ons kan immers alleen vry van die verlede wees deur vry vir die verlede te wees. Aan die ander kant kan ons alleen vry vir die verlede wees deur vry van die verlede te wees. Die eis van bewaring kan nie beteken dat leerstellige formulerings sakrosankt word nie. Dit sal nie alleen die betekenis daarvan in die eie tyd vernietig nie, maar ook die betekenis vir die huidige dag. 'One of the things that can be learned from our traditions is that '(c)ontinual theological reformulation is not new. The history of doctrines is a record of such continual reformulation (Hopper 1987:27).

Miskien is dit juis hier nodig om ook kennis te neem van die waarskuwing van Bonhoefer (1968:14) dat goedkoop genade die doodsvyand van die kerk is. Goedkoop genade is juis genade as beginsel, genade as sisteem, genade as leerstuk. Dit tree na vore wanneer genade beteken dat die instemming met eie leerstuk of dogma vergewing van sonde beteken. Op die wyse word sonde nie ontbloot nie, word eie oorlewering nie krities deurdink nie en word die lewende woord van God in 'n dooie letter of 'n heilige stelsel verander.

Daar is vroeër in die artikel verwys na faktore wat 'n bydrae gelewer het in die ontstaan van belydenisskrifte (vir 'n volledige uiteensetting, kyk Wethmar 1977:9-149). Hierdie vroeë Christelike belydenisse is verder ook aangewend in verskeie kontekste: onder andere as dooponderrig, as deel van die liturgie in die erediens, as simbool by duiweluitdrywing, as verweerskrif en as afgrensing teen dwaalleer.

Alhoewel die onderskeid tussen ortodoks en dwaling deur baie gesien word as die vernaamste konteks van konfessies en dogmas, was dit nie in die vroeë Christendom die geval nie. Vir 'n goeie interpretasie bly dit derhalwe van betekenis dat die breë raamwerk waarbinne die konfessies binne die geloofsgemeenskap gefunksioneer het, in ag geneem sal word. 'They sought to verbalize an experience which meant far more than the words themselves could express' (Hinson 1979:13).

'n Mens sou beide die belangrikheid van konfessionele uitsprake asook die noodsaak van 'n eietydse verstaan kon bepleit met 'n argument van A van de Beek (1996: 137vv). Alhoewel die argument by Van de Beek in 'n ander konteks figureer, sou dit met apologie aan hom goedskiks hier van toepassing kon wees. Hy wys daarop dat geloofsuitsprake van Christene vol innerlike teësprake is. Teologies sou dit moontlik wees om ' $n$ poging aan te wend om sulke uitsprake met mekaar te versoen. Sulke pogings blyk egter meesal onsuksesvol te wees. Selfs by die groot kruispaaie in die teologiegeskiedenis waar dogmas vasgestel is, het dit nie daarom gegaan om konflikterende gedagtes tot 'n sluitende sisteem saam te voeg nie, maar om vas te stel hoe selfs die een en die ander gesê moet word. So is by Chalcedon nie probeer om die godheid en mensheid van Christus saam te voeg nie, maar is vasgestel dat oor Christus as God en as mens gepraat moet word. By die sinode van Dordrecht is teen die opkomende 
protestantse skolastiek in, volgehou dat mense deur God gepredestineer is vir hulle ewige lot en dat hulle tegelyk verantwoordelik is vir hulle eie verlorenheid. Volgens Van de Beek soek die teologie te veel na logiese konsistensie. Hy wys daarop dat terwyl die dubbelheid tot die wese van natuurwetenskaplike teorie hoort, is dit eienaardig dat teoloë vir so ' $n$ dubbelheid bang is.

In die dialektiese teologie het die dubbelheid van uitsprake sterk op die voorgrond getree. Die uitgangspunt was dat dit nie moontlik is om met een woord oor God te praat nie. In 'n gesprek oor God moet die ja die nee deurkruis. Derhalwe is 'n teologiese gesprek 'n lewende gesprek waarin jy nooit volledig gesê kry nie en ook nooit goed gesê kry nie. Dit lei tot versigtigheid vir sisteemdenke en skram ook weg van 'n poging om geopenbaarde waarhede as vasstaande stellings te poneer. Toegepas op die belydenis dat die Bybel God se woord is, sal hierdie benadering beteken dat iemand wat sê dat die Bybel God se Woord is in die sin dat dit geinspireer is, aan die nee wat hierdie $j a$ deurkruis herinner moet word: Die Bybel is 'n menslike boek. So 'n stelling soos bogenoemde kan immers lei tot afgodediens en beeldediens. Wanneer iemand die gevaar loop om te verstar in die gedagtegang dat die Bybel alleen maar' $n$ menslike dokument is wat van godsdienstigheid getuig, sal hy aan die Nee herinner moet word wat so 'n $J a$ deurkruis: Die Bybel is die Woord van God. Bogenoemde moet egter nie so verstaan word dat die een sowel as die ander waar is nie; maar eerder dat die een in die ander waar is (Van Niftrik 1948:56vv).

Van de Beek (1996:138) wys daarop dat alhoewel dit lyk of die meervoudigheidvan teologiese uitsprake in die dialektiese teologie voorkeur geniet, dit alleen betrekking het op die uitsprake self. 'De eenheid van de werklikheid van God was by Barth niet in het geding'. By die meerderheid van dialektiese teoloë gaan dit slegs oor die saak dat ons God nie in ons woorde kan vasvang nie. Van de Beek vra dat kerk en teologie moet leef met die oortuiging dat dit nie net oor die meerduidigheid van ons spreke gaan nie, maar ook daaroor dat die werklikheid self nie eenduidig aangedui kan word nie.

Ter wille van diversiteit van de ervaren werklikheid (en een andere ken $i k$ niet) en om de ervaringen reg te doen, houdt ik vast aan de meervoudigheid van Gods openbaring en, aangezien ik geen andere God ken dan die zich openbaart, aan de meervoudigheid van God zelf. Daarom opteer $\mathrm{ik}$ ook voor een hoge triniteitsleer. Daarin zeggen we zowel dat God zich volledig openbaart in Jesus Christus als dat Hÿ zich in zijn wezen openbaart in de natuur.'

(Van de Beek 1996:140) 
Om te onderstreep dat in teologiese denke dié gedagtegang nie vreemd is nie verwys hy dan na Artikel 2 van die Nederlandse Geloofsbelydenis waar gestel word dat God in die natuur geken kan word. 'Dit is immers voor ons oë soos 'n mooi boek waarin alle skepsels, groot en klein, die letters is wat ons die onsigbare dinge van God, naamlik sy ewige krag en Goddelikheid, duidelik laat sien' (Diensboek 1987:133).

Die kritiek teen die artikel van die NGB spruit volgens Van de Beek, uit die standpunt dat hier aan die uniekheid van God se openbaring in Jesus Christus afbreuk gedoen word. Hy wys egter daarop dat die kritiek alleen standhoudend kan wees 'als we over God denken in de volstrekte eenvoud van het absolute' (1996:140). Indien die erkenning van die gevarieerdheid van geloofsuitsprake in die Christelike geloof ook na die gevarieerdheid van die ervaring met God dui, sou die artikel nie problematies wees nie. Wanneer na 'n eietydse verstaan van die belydenisskrifte gekyk word en pluraliteit in ons huidige konteks ernstig geneem word, behoort Van de Beek se pleidooi nie op dowe ore te val nie. Hy dui immers oortuigend aan op grond waarvan sy standpunt oorweging verdien en dat dit ook nie die Christelike geloof vernietig nie, maar juis verryk.

Dat die dialektiese idioom in die beoefening van teologie binne die Nederduitsch Hervormde Kerk hoog aangeskryf is, is waar. Dit lyk logies dat juis die dialektiese idioom en die uitgangspunte daarvan die verdere treë wat Van de Beek gee, moontlik kan maak. Dit gaan immers om meervoudigheid, nie net van teologiese en kerklike uitsprake nie, maar ook van die belewenis van die werklikheid self.

Hierdie enkele aangeduide motiewe vir 'n eietydse verstaan van die belydenisskrifte onderstreep enkele sake wat van betekenis is.

* Konfessionele uitsprake is belangrik omdat dit iets van die identiteit van die kerk verwoord.

* 'n Verstarring van die uitsprake is vir die kerk en teologie gevaarlik.

* Die uitsprake bind die kerk van gister en vandag onlosmaaklik aanmekaar.

* Belydenisuitsprake verwoord nie alleen iets oor God nie, maar sê ook iets van die mens self.

* Die eietydse konteks vra na 'n eietydse verwoording. Tog is die band met die verlede so belangrik dat die stem van die hede nie sonder die stem van die verlede hoorbaar gemaak kan word nie. Omdat dit die kerk van vandag is wat tot die daad 
van belydenis opgeroep word en nie die kerk van gister nie, is hier tegelyk van kontinuiteit en diskontinuïteit sprake. Juis in hierdie spanningsveld daar reg geskied word aan die oproep tot 'n belydenis Coram Deo.

Verder moet in gedagte gehou word dat juis die verborge teenwoordigheid van God in sy Openbaring ons tot nuwe denke en spreke lei. Die wyse waarop ons die struikelblok van die vlees in ons soeke na God gaan oorkom, het ook te doen met selfverloëning en aanbidding van die misterie van God se teenwoordigheid. 'Onder die spanning van vir die mense alles te word en te staan by Christus wat gekruisig is moet die evangelie steeds in ander taalvelde oorgeklank word. In hierdie oorklanking moet nie by die tydsgees aangepas word nie maar moet in taal en begrippe van die tyd tydgenote tot bevryding en bekering geroep word' (Koekemoer 1989:6). Daarom is 'n eietydse verstaan en verklanking van om belydenisskrifte vir ' $n$ eie belydenis van soveel betekenis.

\section{Literatuurlys}

Bonhoeffer, D 1968. Navolging. Amsterdam: W Ten Have.

Case, S J 1946. The origins of the Christian supernaturalism. Chicago: University of Chicago Press.

Crawford, R G 1976. The revolt against creeds and confessions of faith. Scottish Journal of Theology 29/1, 13-25.

Hinson, E G 1979. Confessions or creeds in Early Christian tradition. Review and Expositor 76/1, 5-13.

Hopper, J 1987. Modern Theology, II. Philadelphia: Fortress.

Jüngel, E 1995. Theological Essays, II, tr by J B Webster. Edinburgh: T \& T Clark. Koekemoer, J H 1989. Dogmatiek binne konfessionele verband. Pretoria: Universiteit van Pretoria.

Omen, T B 1975. The hermeneutic of dogma. Missoula: Scholars Press.

Nederduitsch Hervormde Kerk van Afrika 1983. Diensboek. Pretoria: Kital.

Ott, H 1981. Die Antwort des Glaubens. Berlin: Kreuz Verlag.

Van de Beek, A 1996. Schepping: De wereld als voorspel voor de eewigheid. Baarn: Callenbach.

Van Niftrik, G C 1948. Een beroerder Israels. Nijkerk: Callenbach.

Weber, O 1955. Grundlagen der Dogmatik. Neukirchen: Moers.

Wethmar, C J 1977. Dogma en verstaanshorison. Amsterdam: Redopi. 